
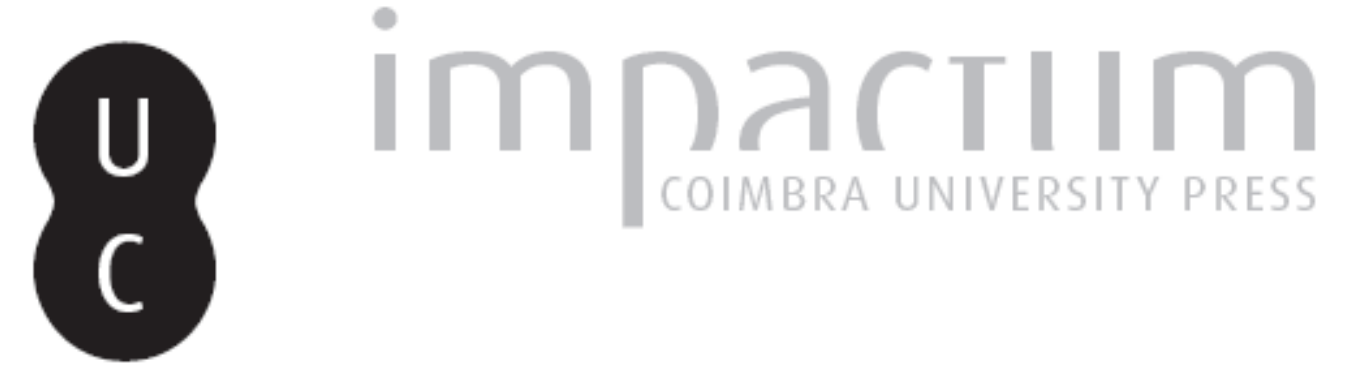

\title{
A epígrafe latina como elemento didáctico (XXIV)
}

\author{
Autor(es): $\quad$ Encarnação, José d'
}
Publicado por: Associação Portuguesa de Estudos Clássicos; Instituto de Estudos Clássicos

URL persistente:

URI:http://hdl.handle.net/10316.2/30434

DOI:

DOI:http://dx.doi.org/10.14195/0872-2110_50_5

Accessed : $\quad$ 26-Apr-2023 13:13:59

A navegação consulta e descarregamento dos títulos inseridos nas Bibliotecas Digitais UC Digitalis, UC Pombalina e UC Impactum, pressupõem a aceitação plena e sem reservas dos Termos e Condições de Uso destas Bibliotecas Digitais, disponíveis em https://digitalis.uc.pt/pt-pt/termos.

Conforme exposto nos referidos Termos e Condições de Uso, o descarregamento de títulos de acesso restrito requer uma licença válida de autorização devendo o utilizador aceder ao(s) documento(s) a partir de um endereço de IP da instituição detentora da supramencionada licença.

Ao utilizador é apenas permitido o descarregamento para uso pessoal, pelo que o emprego do(s) título(s) descarregado(s) para outro fim, designadamente comercial, carece de autorização do respetivo autor ou editor da obra.

Na medida em que todas as obras da UC Digitalis se encontram protegidas pelo Código do Direito de Autor e Direitos Conexos e demais legislação aplicável, toda a cópia, parcial ou total, deste documento, nos casos em que é legalmente admitida, deverá conter ou fazer-se acompanhar por este aviso.

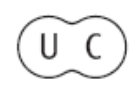




\section{Boletim de \\ Estudos Clássicos}

Associação Portuguesa de Estudos Clássicos Instituto de Estudos Clássicos

\section{Coimbra}

Dezembro de 2008 


\section{A EpíGrafe latina como Elemento Didáctico (XXIV)}

\section{Contaminação ou aculturação}

A recente descoberta de mais um documento epigráfico em que há palavras susceptíveis de se filiarem no estrato linguístico a que se convencionou chamar de «lusitano» sugeriu-me que dedique umas linhas a um tema que, no âmbito do aproveitamento das inscrições romanas como «elemento didáctico», poderá deter algum interesse.

$\mathrm{Na}$ verdade, sabe-se que os textos literários latinos podem reflectir idiotismos cuja origem radica em 'dialectos' preexistentes. Ou seja, que, quando os Romanos chegaram a um território, os indígenas tinham, naturalmente, a sua língua e o que ocorreu foi que, em contacto, paulatinamente se verificou uma «contaminação» ou, para usarmos o vocábulo retirado da Antropologia Cultural, uma «aculturação»: palavras latinas passaram a ser usadas pela população indígena, palavras de 'sabor' pré-latino entraram no vocabulário corrente envergando vestes latinas.

Como para as epígrafes o que amiúde se passa são os antropónimos e os teónimos, uma vez que os formulários latinos se terão imposto sem dificuldade, será, de modo especial, a análise etimológica de teónimos e de antropónimos que nos tem permitido definir, na medida do possível, a proveniência dessas «contaminações».

Facilmente se suspeita que se trata, de facto, de uma pesquisa aliciante, pelas conclusões a que permite chegar - inclusive nos planos social, político e económico até - descobrir como os diferentes 'povos' se inter-relacionaram.

Desde finais do século XIX que esse é, consequentemente, um domínio que vem aliciando os investigadores peninsulares, ciosos de tentarem descortinar, em cada uma das 'parcelas' ibéricas, que 'povo' distinto dos demais (justificador de uma identidade própria, compreende-se...) esteve na sua origem. E não nos surpreenderá saber que, exactamente na mesma altura em que os peninsulares começavam a conviver com os Romanos recém-chegados, aí pelo século II a.C., também essa convivência ocorria numa região como o Sudeste da Península Itálica, onde a mescla das 
influências da civilização local messápica, dos Gregos e dos Romanos é bem visível tanto nos dados arqueológicos ${ }^{1}$ como na coexistência de inscrições em língua grega e em latim².

No caso do território hispânico, consideraram-se de língua «lusitana» os textos identificados em Lamas de Moledo (Castro Daire), em Cabeço das Fráguas (Pousafoles, Sabugal) e três outros em Arroyo de la Luz já em território espanhol ${ }^{3}$. Não houve uma justificação cientificamente documentada - nem o podia haver - para essa hipótese de trabalho, lançada pelo Prof. António Tovar ${ }^{4}$. Contudo, trata-se, sem dúvida, de uma explicação plausível, dado que nesses textos, a par de palavras latinas, outras surgem que, de aparência latina - pela grafia e pela flexão -, não parecem susceptíveis de se relacionar com etimologias conhecidas do léxico latino.

A epígrafe identificada em Arronches, em meados de 2007, dado que contém palavras também existentes nos textos de Cabeço das Fráguas e de Lamas de Moledo, não hesitámos, pois, em a considerar «lusitana» 5 .

${ }^{1}$ Veja-se, a título de exemplo: Katia Mannino, Vasi Atici nei Contesti della Messapia (480-350 a.C.), Bari, 2006.

2 A cidade de Bari disso pode considerar-se um paradigma: Andreassi (Giuseppe) e Radina (Francesca) [coord.], Archeologia di una Città - Bari dalle Origini al X Secolo, Bari, 1988. Veja-se sobretudo o capítulo da documentação epigráfica, da responsabilidade de Marcella Chelotti, Vincenza Morizio e Marina Silvestrini (p. 439-456).

3 Bibliografia actualizada em: Francisco Villar e Rosa Pedrero, «La nueva inscripción lusitana: Arroyo de la Luz III», in Villar (Francisco) e Fernández Álvarez, M. ${ }^{a}$ Pilar, Religión, Lengua y Cultura Prerromanas de Hispania, Salamanca, 2001, p. 663-698.

${ }^{4}$ António Tovar, «La inscripción del Cabeço das Fráguas y la lengua de los lusitanos», Actas del III Coloquio sobre Lenguas y Culturas Paleohispánicas (Lisboa 1980), Salamanca, 1985, p. 227-253.

5 O monumento foi dado a conhecer, em Évora, no VII Congresso Internacional da APEC (Associação Portuguesa de Estudos Clássicos), subordinado ao tema Espaços e paisagens - Antiguidade Clássica e heranças contemporâneas, na comunicação «Epígrafe votiva de Arronches - Notícia da sua identificação», apresentada, a 10 de Abril deste ano de 2008, por André Carneiro, José d'Encarnação, Jorge de Oliveira e Cláudia Teixeira. Será, pois, publicado nas respectivas actas. Desse estudo prepararam os autores duas versões mais completas, ligeiramente diferentes, destinadas às revistas Conimbriga de 2008 (vol. XLVII) e Palaeohispanica $(8,2008)$. 
Estamos perante um texto votivo, relacionável, mui provavelmente, com os rituais ligados à transumância: cientes da sua dependência dos factores atmosféricos, da segurança nas rotas e, por consequência, das divindades que a toda essa vivência presidiam, os criadores de gado aproveitariam a passagem por locais mais impregnados de religiosidade, por altura quiçá das necessárias paragens, para oferecerem em sacrifício às diversas divindades algumas cabeças de gado.

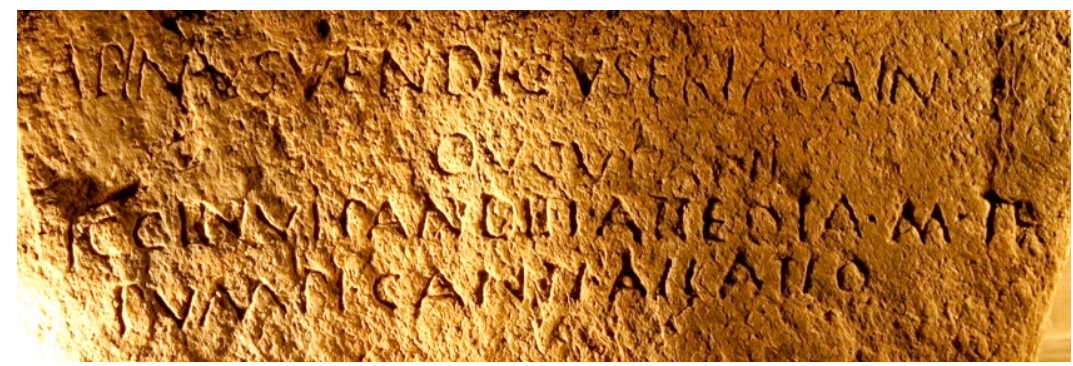

Numa primeira parte, interpretámos nós, dir-se-á o que se oferece e a quem; na segunda, identificar-se-ão os dedicantes e far-se-á a súplica final a requerer as boas graças dos númenes invocados.

Como o que ora nos interessa são - na sequência das anteriores reflexões - as questões linguísticas, vejamos o que se escreve no começo dessa " 2 a parte" (foto):

\section{APINVS • VENDICVS • ERIACAINV[S] OVOVIANI}

Comentávamos, no texto da citada revista Palaeohispanica:

«Apinus é antropónimo com outros testemunhos já, inclusive na Lusitânia, registando-se, por curiosa coincidência, a forma Appinnae em Lamas de Moledo.

Vendicus ainda não terá surgido atestado sob esta forma, que saibamos; contudo, um radical vend- é reconhecível em antropónimos como Vendalo, Vendieci, Vendio, Vendiricus, pelo que será facilmente admissível, para mais com a terminação -icus.

Eriacainus é, por seu turno, o único nome para o qual se não encontra, de momento, palavra aproximável, ainda que seja aliciante, neste contexto, 
atribuir-lhe uma relacionação com a raiz, «atestada em quase todas as línguas indoeuropeias», *er-, a que os celtistas atribuem a conotação de 'chibo, cordeiro, vaca, gamo', na origem, 'animais com cornos'». ${ }^{6}$

E, no que concerne à palavra da linha seguinte - OVOVIANI [?] -, apontámos que a aparente relacionação deste estranho vocábulo com ovis, "ovelha", nos poderia levar a pensar que se trata de uma referência... 'profissional': os pastores ou os comerciantes de ovelhas, os 'ovelheiros'.

Por conseguinte, para além da 'contaminação' da linguagem escrita pela linguagem falada, patente, como se sabe, nos diálogos teatrais e, também, nos documentos epigráficos, estoutra 'contaminação' de estratos linguísticos (expressão que se usa à falta de melhor) constitui mais um aliciante para que as epígrafes possam aproveitar-se como sugestivos elementos didácticos.

JOSÉ D’ENCARNAÇÃO

6 Cf. Albertos Firmat, M ${ }^{\mathrm{a}}$ Lourdes, La Onomastica Personal Primitiva de Hispania, Salamanca, 1966, p. 116. 